\title{
A glimpse into the black box of celiac disease complications: a case report with a rare presentation
}

\author{
Natalya Viktorovna Rylova, Ahmed Arafat, Almazia Raisovna Shakirova, Ilyuza Shaidullina, Rozaliya Zakirova \\ Department of Pediatrics, Kazan State Medical University, Kazan, Russia
}

Gastroenterology Rev 2021; 16 (2): 111-116

DOI: https://doi.org/10.5114/pg.2021.106661

Key words: celiac disease, hypopituitarism, hypothyroidism, case report, growth hormone deficiency.

Address for correspondence: Ahmed Arafat MD, PhD, Department of Pediatrics, Kazan State Medical University, Kazan, Russia, phone: +79270444210, e-mail: dr.a.zaher@hotmail.com

\begin{abstract}
The purpose of this article is to report a case of celiac disease in a child with uncommon presentation and severe complications, and briefly review recent literature regarding celiac disease complications in children. We describe a case report of celiac disease in a child (to our knowledge, this is the first to be reported in its unique presentation in the Russian Federation) and precisely review its presenting complications with the exiting works of literature. Many cases of celiac disease in children who are not diagnosed and treated properly suffer from a plethora of complications due to malabsorption and concurrent autoimmune reactions that affect mainly but are not limited to the endocrine system. Complications of celiac disease in children should always be suspected, and evidence-based follow-up recommendations should be introduced as soon as possible because the burden of celiac disease complications in children is remarkable.
\end{abstract}

\section{Introduction}

Celiac disease (CD) was previously considered a childhood disease that causes malabsorption and various digestive problems that dramatically affect children's development, and it has a huge impact on their cognitive and developmental milestones. It is now known to be an immune-mediated disease that can affect any age group, and it has genetic characteristics that make some individuals more susceptible than others. It is triggered by the ingestion of gluten-containing products such as bread, barley, food pastes, and wheat [1].

In clinical practice CD frequently goes underdiagnosed due to its wide clinical presentations in children that could mimic any other disease of the endocrine system, or maybe due to its early exclusion from the differential diagnosis, especially in populations where its prevalence is not high. On the other hand, delayed onset of $C D$ around the age of 5-7 years might be presented with uncommon gastrointestinal complaints (e.g. vomiting, recurrent abdominal pain, nausea) or other non-gastrointestinal presentations, such as iron deficiency, delayed puberty, dental enamel deformities, and short stature [2]. What is considered as a real challenge is the diagnosis in cases that only present with short stature as the main symptom [3]. Some works of literature on CD have described patients with short stature and CD, low levels of somatomedin, and normal release of growth [4]. Nevertheless, cases of growth hormone deficiency associated with CD are also reported [5]. The pituitary gland may well be a target for the autoimmune process in celiac disease [6]. Children with hypopituitarism and short stature associated with CD are not yet well-explained in the literature, the goal of this study was to briefly assess this relationship.

Written informed consent was collected from our patient and his caregiver (mother). This case report was approved by Kazan Medical State University and the Republican Children's Clinical Hospital Medical Ethics Committee.

\section{Case presentation \\ Patient}

A male child, who was born from the second pregnancy of apparently healthy parents with irrelevant family history, and whose brother is a healthy male. The father's height is $168 \mathrm{~cm}$ and the mother's is $154 \mathrm{~cm}$. Since his early childhood, the patient developed symptoms of bloating, abdominal pain, and discomfort. 
When the family started to notice his lag of growth behind his peers at the age of 9 years old, they turned to a paediatrician, who subsequently referred them to the endocrinology department of the Republican Children's Clinical Hospital of Kazan, Russia. Examination and laboratory analysis determined the diagnosis of "hypopituitarism and growth hormone deficiency".

\section{Physical examination and laboratory testing}

Upon examination, the child's height was $113 \mathrm{~cm}$ (less than the third percentile for a 9-year-old), his weight was $20 \mathrm{~kg}$ (less than the third percentile for a 9-year-old).

According to clinical and laboratory studies, the following deviations were detected (Table I).

\section{Growth hormone stimulation tests}

In this study, we used 2 standard provocation tests, insulin, and oral clonidine. In the test, clonidine (Clophelin ${ }^{\circledast}$, Russia) was administered orally at a dose of $0.15 \mathrm{mg} / \mathrm{m}^{2}$. Blood samples were withdrawn before administration of Clonidine and 30, 60, 90, and 120 min after administration of the medicine (respectively). In a hypoglycaemic test, short-acting insulin (Actrapid ${ }^{\circledast}$, Novo-Nordisk, Denmark) was administered intravenously at a dose of $0.1 \mathrm{lU} / \mathrm{kg}$. Blood samples were withdrawn before the injection of insulin and 15, 30, 45, 60, 90, and 120 min after administration of the medicine (re- spectively); at the same time, the blood glucose level was carefully monitored.

Determination of the concentration of growth hormone in the blood serum was carried out using standard sets from the "Hema-Medica» company using the ADOL (immunofluorescence assay) method in the laboratory of the Republican Children's Clinical Hospital of Kazan, Russia, which is certified to conduct these laboratory assessments. A comparison of the results was performed following the instructions for the test kits and analysed within the established range of normal concentration of hormones (Table II).

\section{Interventions}

Based on the results of the MRI of the brain and the stimulation tests, our case was diagnosed with growth hormone deficiency (GHD). Our case was given the green light to start the treatment of GHD with Somatropin, recombinant human growth hormone (Rastan ${ }^{\oplus}$, Russia), at a dose of $0.594 \mathrm{mg} / \mathrm{day}$, which was regularly adjusted (increased) according to body weight.

In April 2016 (11 years old), the patient for the first time started to develop some complaints of dyspeptic phenomena (abdominal pain, bloating, and violation of the stool in the form of a mushy stool). At this time, the child's height was $120 \mathrm{~cm}$, and the height gain was $7 \mathrm{~cm}$ in 20 months (Figure 1).

Laboratory investigations revealed hypochromic anaemia, with a haemoglobin of $88 \mathrm{~g} / \mathrm{l}$, magnetic res-

Table I. Laboratory and radiology values during inpatient evaluation (first visit at the age of 9 years)

\begin{tabular}{lccc} 
Parameter & Value & Unit & Normal range \\
\hline Haemoglobin & 101 & $\mathrm{~g} / \mathrm{l}$ & $110-150$ \\
\hline Insulin-like growth factor 1 (IGF-1) & 82.7 & $\mathrm{ng} / \mathrm{ml}$ & Chronological age: 9 \\
\hline Age & Bone age (hand radiology): & years & $\mathrm{mlU} / \mathrm{ml}$ \\
\hline MRI & $\mathrm{NAD}$ & $\mathrm{pmol} / \mathrm{l}$ & $0.3-5.0$ \\
\hline TSH & 1.81 & $\mathrm{nmol} / \mathrm{l}$ & $11-26$ \\
\hline Free T4 & 11.66 & $28-1049$
\end{tabular}

MRI - magnetic resonance imaging, TSH - thyroid-stimulating hormone, free T4 - thyroxine.

Table II. Growth hormone stimulation tests results $(\mathrm{ng} / \mathrm{ml})$

\begin{tabular}{lcccccc} 
Variable & $\begin{array}{c}\text { Before the } \\
\text { introduction }\end{array}$ & At $\mathbf{1 5}$ min & At $30 \mathrm{~min}$ & At 45 min & At 60 min & At 90 min 120 min \\
\hline $\begin{array}{l}\text { Clophelin } \\
(0.12 \text { mg dose) }\end{array}$ & 4.2 & - & 5.8 & - & 3.96 & 7.53 \\
\hline $\begin{array}{l}\text { Insulin (dose of } \\
2 \text { units) }\end{array}$ & 0.4 & 0.5 & 0.4 & 1.25 & 2.5 & 2.07 \\
\hline
\end{tabular}

The level of the hormone is within the limits of 7-10 $\mathrm{ng} / \mathrm{ml}$, which indicates a partial deficit of growth hormone. 
onance imaging (MRI) of the pituitary was normal, and thyroid function tests showed a decrease in T4 to $0.75 \mathrm{ng} / \mathrm{dl}$ (normal range $0.78-1.34 \mathrm{ng} / \mathrm{dl}$ ), which exemplified secondary hypothyroidism. To correct the level of T4, levothyroxine was prescribed at a dose of $25 \mu \mathrm{g} /$ day. Against the background of levothyroxine intake, T4 values normalized. The doses of levothyroxine are shown in Table III.

Fibrogastroduodenoscopy (FGDS) showed pale and atrophied post-bulbar duodenum and the proximal part of the jejunum, and serological studies showed positive celiac-specific serology (IgA anti-tissue transglutaminase antibody and IgA endomysial antibody).

The duodenal biopsy showed grade 3 (C) subtotal atrophy of the villi, with a decreased villous-to-crypt ratio, increased cellularity of the lamina propria with a proliferation of lymphocytes and plasma cells, and an increased number of intraepithelial lymphocytes per unit length of absorptive epithelium 3-4 : 10 (normal intraepithelial lymphocyte to epithelial cell ratio, $1: 10$ ).

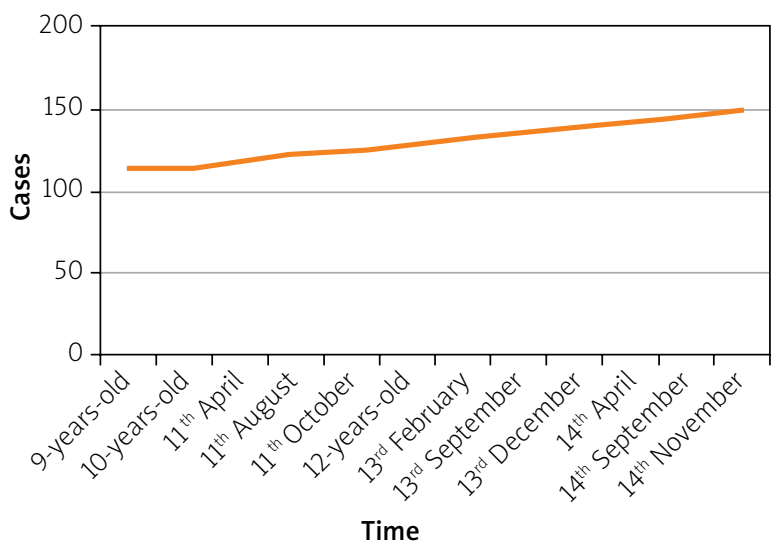

Figure 1. The flow chart of our case's height. Upon the first examination (9-years-old), the child's height was $113 \mathrm{~cm}$ (less than the third percentile height), after treatment with Somatropin, in April 2016 (11-years-old), the child's height was $120 \mathrm{~cm}$, the height gain was $7 \mathrm{~cm}$ in 20 months

Table III. Doses of levothyroxine

\begin{tabular}{|c|c|c|c|c|c|c|c|c|}
\hline & \multicolumn{8}{|c|}{ Age } \\
\hline & $11 \mathrm{y}$ & 11 y $6 \mathrm{~m}$ & $12 y$ & 13 y $3 \mathrm{~m}$ & 13 y $6 \mathrm{~m}$ & 13 y $9 \mathrm{~m}$ & $14 y$ & 14 y $6 \mathrm{~m}$ \\
\hline L-thyroxine $[\mu \mathrm{g}]$ & 25 & 33 & 50 & 62.5 & 75 & 87.5 & 100 & 100 \\
\hline
\end{tabular}

$y$-year, $m$ - month
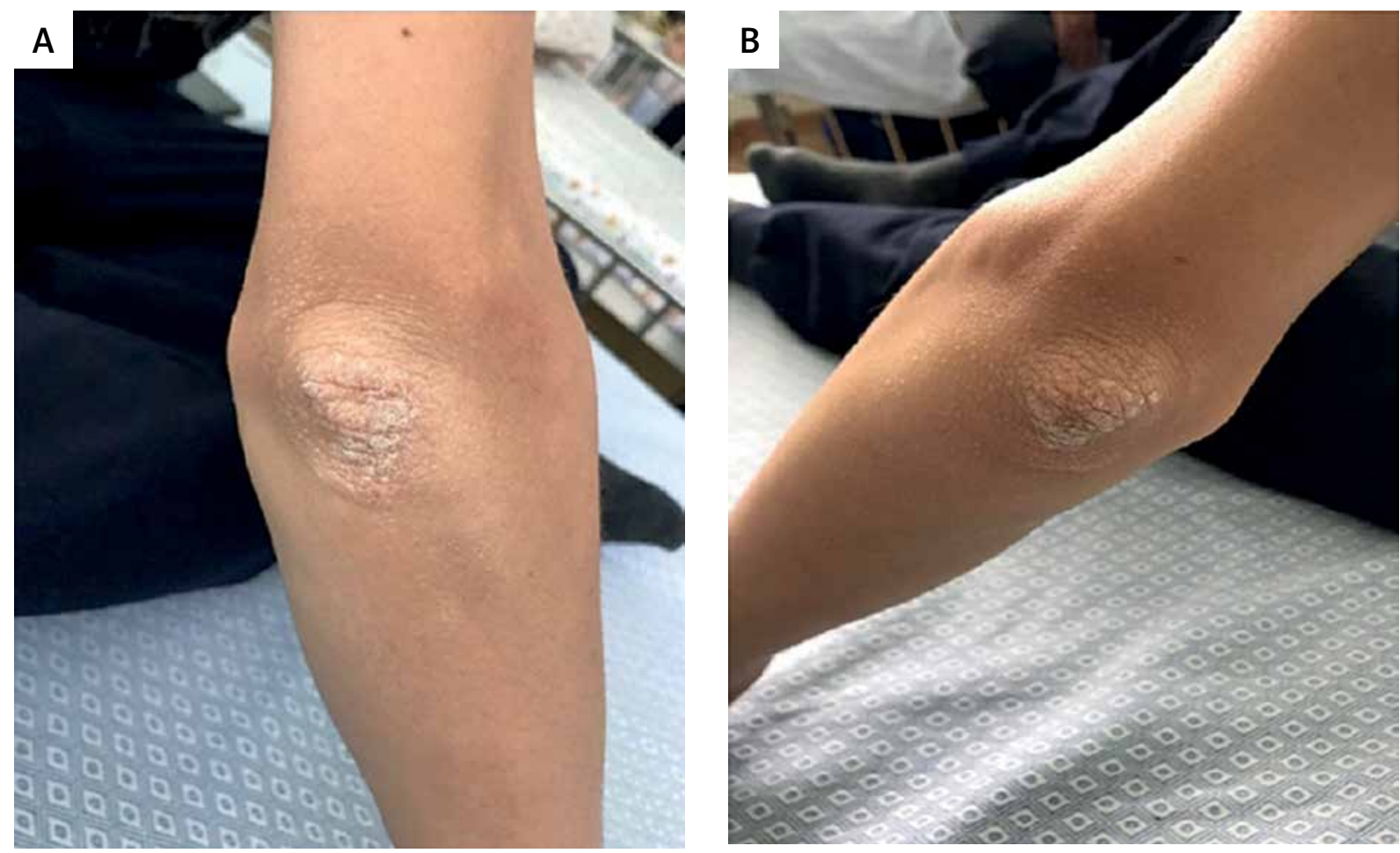

Figure 2. Psoriasis of the right and left elbows. Silvery-white scales on the extensor surfaces of both elbows: A - right elbow, B - left elbow 
The above data allowed us to establish and justify the diagnosis: celiac disease, typical form, latent course.

At the age of 14 years and 6 months (upon his latest follow-up visit), our case had a rare presentation among children with CD: silvery-white scales and eczema on the extensor surface of both of his elbow joints, which was diagnosed as psoriasis, and was referred to the dermatologists for treatment (Figure 2).

Currently, our patient is on a gluten-free diet, and his enteropathy complications ease when he stays adherent to the diet.

\section{Discussion}

We herein report a case of CD with a typical form and latent course, in a child who developed signs of growth hormone deficiency, hypopituitarism, psoriasis, and hypothyroidism. His enteropathy symptoms, which are the most common presentation of CD, did not draw the attention of his parents, but his short stature for his age and lagging behind his peers was what brought them to the outpatient clinic for help.

\section{Association between $\mathrm{CD}$ and thyroid disease}

The association between CD and both hyper- and hypothyroidism have been highly expressed in $\operatorname{CD}[7,8]$. Works of literature have shown that adherence to a gluten-free diet may minimize the possibility of escalating autoimmune disorders, suggesting that endocrine immunity could be due to chronic uncontrolled inflammation [9].

The pervasiveness of hypothyroidism is demonstrated in various studies to be 3 to 4 times higher risk in CD patients compared to the controls [7, 10]. A large recent study of 14,021 patients with $C D$ found that the risk of hypothyroidism and hyperthyroidism and thyroiditis increased by 2.9 to 4.4 times compared to the general population or controls [8]. The effect of a gluten-free diet in correcting ongoing thyroid dysfunction has not yet been determined because several studies have shown conflicting results, with one study stating that firm adherence to a gluten-free diet may correct normalized subclinical hypothyroidism [10], but with other studies failing to prove so [11].

The momentum that those studies have added has favoured the recommendation of screening CD patients for thyroid function; this recommendation is also backed by both the American Association of Clinical Endocrinologists and the American Thyroid Association, especially in those with autoimmune disease [12]. It is suggested to suspect CD in patients with hypothyroidism those are not showing the expected response to levothyroxine, because the malabsorption that ensues
CD might interfere with the treatment [13]. Serologic analysis of $C D$ is recommended for patients of hypothyroidism requiring more than or equal to $125 \mu \mathrm{g} /$ day of levothyroxine, as suggested by one study [14].

\section{Association between $\mathrm{CD}$ and growth hormone deficiency}

Consistently with our report, many studies have reported that in children, failure to thrive or short stature could be the initial sign of CD [15, 16]. A gluten-free diet helps most children with short stature and CD to catch up growth [16]. An Italian study reported that among children with short stature, $0.23 \%$ had both growth hormone deficiency and CD, and $0.63 \%$ had CD [17]. Concurring with the findings in our report, a gluten-free diet and growth hormone administration as combined treatment in children with growth hormone deficiency and $C D$ can increase their growth rate [16].

\section{Association between CD and short stature}

The prevalence rate of short stature among CD patients has been an area of interest for many studies; isolated short stature cases in the absence of GIT symptoms has shown a prevalence rate between $2 \%$ and $8 \%$ $[18,19]$. In a recent Saudi study of 275 children with isolated short stature reported a CD prevalence rate of $5.8 \%$ and seropositivity prevalence rate of $13.8 \%$ [20]. Short stature in CD children with GIT symptoms likewise has a high prevalence rate. A study from Egypt reported a $6.6 \%$ prevalence rate of CD among children with short stature [21]. An Indian team conducted a study on 432 children with short stature and CD with GIT symptoms, and they showed an interesting prevalence rate of $10.9 \%$ [22]. Thus, short stature unignorably presents in CD children whether GIT symptoms coexist or not.

\section{Association between CD and hypopituitarism}

Celiac disease autoimmune involvement of the pituitary gland is not adequately presented in the literature, although there are clinical and laboratory findings to support such a hypothesis. In children with CD, impairment of the growth hormone-IGF-1 axis has been frequently reported before the administration of a gluten-free diet [17], and it is generally corrected after the institution of said gluten-free diet [23]. An Italian study reported for the first time the presence of anti-pituitary antibodies (APA) in newly diagnosed children with CD, thus establishing a backbone for autoimmune involvement of the pituitary gland [24]. Another study suggested the development of autoimmune hypophysitis 
in children with CD who fail to catch up growth after being adherent to a gluten-free diet [25].

\section{Association between CD and dermatologic manifestation (psoriasis)}

CD patients are prone to develop skin conditions that vary from a nonspecific rash to psoriasis, eczema, atopic dermatitis, urticaria, and dermatitis herpetiform dermatitis [26].

The incidence of psoriasis among children with $C D$ patients unlike adults is not yet expressed adequately in the literature. Several studies have discussed the benefit of a gluten-free diet on improving the severity of psoriasis in CD patients, and the explanation of such an effect of a gluten-free diet on the improvement of psoriasis could be due to the improvement of the function of the intestinal barrier or adequate absorption of vitamin D [27]. Some authors claim that psoriasis is likely to be the main clinical presentation of CD [27] Also, typical CD antibodies such as anti-tTG, anti-endomysium IgA IgA and antigliadin IgA, IgG antibodies show a remarkable increase in psoriasis patients [28].

\section{Conclusions}

$C D$ has a huge impact on children, which, if not promtly diagnosed and managed, might go misdiagnosed with other similar endocrinal diseases or GIT illnesses. Not all CD complications develop at the same time, and the inflammatory and/or immune response take time to develop in each case individually. Genetic causes might play a role in CD pathogenesis, and further studies are needed to investigate this hypothesis. During the course of CD, especially in children, some complications tend to frequently occur, such as growth hormone deficiency or hypothyroidism; although hypopituitarism and psoriasis are comparably rare complications of $C D$, they should be suspected in CD patients who exhibit atypical course. It worth mentioning that CD patients might have hyposplenism and weak response to vaccinations and higher susceptibility to infection with encapsulated bacteria [29]. With that being said, monitoring, screening, and early treatment will benefit many patients, especially children.

Evidence-based recommendations for follow-up of children with $C D$ are lacking. Follow-up of these children should be firmly done 6 months after diagnosis and treatment initiation and then yearly, to check their symptomatic improvement, their response to treatment, and their adherence to a gluten-free diet, as well as to check if any modification of treatment is needed. Due to the unique presentation of $C D$ in each patient, their follow-up plans should subsequently be tailored for each case.
It has been reported that children with $C D$ rarely develop complications, and only a few cases have been reported [30]. In contrst to such reports, our case had multiple complications. Therefore, an up-to-date mindset is needed to thoroughly investigate children with CD and to be ready to deal with its various presentations and effectively manage its plethora of complications that can affect almost all the body systems.

\section{Acknowledgments}

Natalya Viktorovna Rylova and Ahmed Arafat equally contributed to this work.

\section{Conflict of interest}

The authors declare no conflict of interest.

\section{References}

1. Lebwohl B, Sanders DS, Green PHR. Coeliac disease. Lancet 2018; 391: 70-81.

2. Fasano A, Catassi C. Current approaches to diagnosis and treatment of celiac disease: an evolving spectrum. Gastroenterology 2001; 120: 636-51.

3. Tumer L, Hasanoglu A, Aybay C. Endomysium antibodies in the diagnosis of celiac disease in short-statured children with no gastrointestinal symptoms. Pediatr Int 2001; 43: 71-3.

4. Day G, Evans K, Wharton B. Abnormalities of insulin and growth hormone secretion in children with coeliac disease. Arch Dis Child 1973; 48: 41-6.

5. Giovenale D, Meazza C, Cardinale GM, et al. The prevalence of growth hormone deficiency and celiac disease in short children. Clin Med Res 2006; 4: 180-3.

6. Collin P, Hakanen M, Salmi JP, et al. Autoimmune hypopituitarism in patients with coeliac disease: symptoms confusingly similar. Scand J Gastroenterol 2001; 36: 558-60.

7. Sun X, Lu L, Yang R, et al. Increased incidence of thyroid disease in patients with celiac disease: a systematic review and meta-analysis. PLoS One 2016; 11: e0168708.

8. Elfstrom P, Montgomery SM, Kampe O, et al. Risk of thyroid disease in individuals with celiac disease. J Clin Endocrinol Metab 2008; 93: 3915-21.

9. Cosnes J, Cellier C, Viola S, et al. Incidence of autoimmune diseases in celiac disease: protective effect of the gluten-free diet. Clin Gastroenterol Hepatol 2008; 6: 753-8.

10. Sategna-Guidetti C, Volta U, Ciacci C, et al. Prevalence of thyroid disorders in untreated adult celiac disease patients and effect of gluten withdrawal: an Italian multicenter study. Am J Gastroenterol 2001; 96: 751-7.

11. Canova C, Pitter G, Ludvigsson JF, et al. Celiac disease and risk of autoimmune disorders: a population-based matched birth cohort study. J Pediatr 2016; 174: 146-52 e1.

12. Garber JR, Cobin RH, Gharib H, et al. Clinical practice guidelines for hypothyroidism in adults: cosponsored by the American Association of Clinical Endocrinologists and the American Thyroid Association. Endocr Pract 2012; 18: 988-1028. 
13. Centanni M, Benvenga S, Sachmechi I. Diagnosis and management of treatment-refractory hypothyroidism: an expert consensus report. J Endocrinol Invest 2017; 40: 1289-301.

14. Zubarik R, Ganguly E, Nathan M, Vecchio J. Celiac disease detection in hypothyroid patients requiring elevated thyroid supplementation: a prospective cohort study. Eur J Intern Med 2015; 26: 825-9.

15. Assiri AM. Isolated short stature as a presentation of celiac disease in Saudi children. Pediatr Rep 2010; 2: e4.

16. Bozzola M, Giovenale D, Bozzola E, et al. Growth hormone deficiency and coeliac disease: an unusual association? Clin Endocrinol 2005; 62: 372-5.

17. Giovenale D, Meazza C, Cardinale GM, et al. The prevalence of growth hormone deficiency and celiac disease in short children. Clin Med Res 2006; 4: 180-3.

18. Troncone R, Kosova R. Short stature and catch-up growth in celiac disease. J Pediatr Gastroenterol Nutr 2010; 51 (Suppl 3) S137-8.

19. Van Rijn JC, Grote FK, Oostdijk W, Wit JM. Short stature and the probability of coeliac disease, in the absence of gastrointestinal symptoms. Arch Dis Child 2004; 89: 882-3.

20. Saadah OI, Alnosani NM. Celiac disease in Saudi children with isolated short stature: is it rare or are we not screening rigorously enough? J Pediatr Endocrinol Metab 2020; 33: 89-93.

21. Hussein A, Farghaly $\mathrm{H}$, Askar E, et al. Etiological factors of short stature in children and adolescents: experience at a tertiary care hospital in Egypt. Ther Adv Endocrinol Metab 2017; 8: 75-80.

22. Singh P, Sharma PK, Agnihotri A, et al. Coeliac disease in patients with short stature: a tertiary care centre experience. Natl Med J India 2015; 28: 176-80.

23. Street ME, Volta C, Ziveri MA, et al. Changes and relationships of IGFS and IGFBPS and cytokines in coeliac disease at diagnosis and on gluten-free diet. Clin Endocrinol 2008; 68: 22-8.

24. Delvecchio $M$, De Bellis A, Francavilla R, et al. Anti-pituitary antibodies in children with newly diagnosed celiac disease: a novel finding contributing to linear-growth impairment. Am J Gastroenterol 2010; 105: 691-6.

25. Iughetti L, De Bellis A, Predieri B, et al. Growth hormone impaired secretion and antipituitary antibodies in patients with coeliac disease and poor catch-up growth aft er a long gluten-free diet period: a causal association? Eur J Pediatr 2006; 165: 897-903.

26. Silvester JA, Graff LA, Rigaux L, et al. Symptomatic suspected gluten exposure is common among patients with coeliac disease on a gluten-free diet. Aliment Pharmacol Ther 2016 44: 612-9.

27. Graziano M, Rossi M. An update on the cutaneous manifestations of coeliac disease and non-coeliac gluten sensitivity. Int Rev Immunol 2018; 37: 291-300.

28. Ojetti V, Aguilar Sanchez J, Guerriero C, et al. High prevalence of celiac disease in psoriasis. Am J Gastroenterol 2003; 98 : 2574-5.

29. Noh KW, Poland GA, Murray JA. Hepatitis B vaccine nonresponse and celiac disease. Am J Gastroenterol 2003; 98: 2289-92.

30. Mubarak A, Oudshoorn JH, Kneepkens CM, et al. A child with refractory coeliac disease. J Pediatr Gastroenterol Nutr 2011; 53: $216-8$
Received: 5.06.2020

Accepted: 10.08 .2020 